\title{
O MONITORAMENTO DO AQUÍFERO CAIUÁ NO PARANÁ PELA REDE RIMAS/CPRM.
}

Eduardo Marcel Lazzarotto ${ }^{1}$; Andrea Segura Franzini ${ }^{2}$; Guilherme Nogueira dos Santos $^{3}$; Isadora Aumond Kuhn ${ }^{4}$

\section{RESUMO}

O Serviço Geológico do Brasil-CPRM está implantando e operando desde 2009 a Rede Integrada de Monitoramento de Águas Subterrâneas (RIMAS). O Aquífero Caiuá é amplamente utilizado no noroeste do Paraná, sendo necessário o acompanhamento quantitativo e qualitativo deste recurso. Os dados de nível da água e pluviométricos foram plotados em gráficos com o objetivo de permitir uma análise conjunta da precipitação e das variações dos níveis estáticos dos poços. Em relação à hidrogeoquímica, os dados foram plotados no "Diagrama de Piper" resultando em águas Cloretadas Magnesianas, Cloretadas Sódicas, Bicarbonatadas Sódicas, Bicarbonatadas Magnesianas e Bicarbonatadas Cálcicas. A análise de correlação entre a carga hidráulica dos diferentes poços, o conteúdo dos cátions maiores, alcalinidade e resíduo seco revelaram correlação negativa significativa, com aumento na mineralização em direção as cargas hidráulicas mais baixas.

\section{ABSTRACT}

The Brazilian Geological Service-CPRM is operating the Integrated Groundwater Monitoring System (RIMAS) since 2009. One of the RIMAS monitored regional aquifers; the Caiuá Aquifer is being largely used in the northwest fringe of the Paraná State in Brazil and therefore needs quality and quantity assessment. Historical data on groundwater level and rainfall were plotted together in order to establish integrated correlations. Regarding the hydrochemistry, the obtained data were used to build a Piper diagram, which reveals magnesium chloride, sodium chloride sodium bicarbonate, magnesium bicarbonate and calcium bicarbonate groundwater types. The analysis between hydraulic head and major ion content, alkalinity and dry residue have showed a significant negative correlation. Higher saline contents are expected in regions bearing groundwater with lower hydraulic heads.

Palavras-chave: Aquífero Caiuá. Paraná. RIMAS.

1 - Companhia de Pesquisa de Recursos Minerais. Rua Costa, 55. São Paulo. (11) 3775-5152 - eduardo.lazzarotto@cprm.gov.br

2 - Companhia de Pesquisa de Recursos Minerais. Rua Costa, 55. São Paulo. (11) 3775-5135 - andrea.franzini@cprm.gov.br

3 - Companhia de Pesquisa de Recursos Minerais. Rua Costa, 55. São Paulo. (11) 3775-5133 - guilherme.santos@ cprm.gov.br

4 - Companhia de Pesquisa de Recursos Minerais. Rua Banco da Província, 105. Porto Alegre. (51) 3406-7363 -

isadora.kuhn@cprm.gov.br 


\section{1 - INTRODUÇÃO}

No Paraná o Aquífero Caiuá situa-se no noroeste do estado e ocupa uma área aproximada de $29.000 \mathrm{~km}^{2}$ (Figura 1). Este aquífero é livre, granular e amplamente utilizado na região para abastecimento público, atividades industriais e agrícolas.

Devido às características e a importância deste aquífero, a Rede Integrada de Monitoramento de Águas Subterrâneas - RIMAS começou a monitorar este aquífero em 2010, com o objetivo de ampliar os conhecimentos hidrogeológicos através das análises das variações espaciais e temporais na quantidade e na qualidade das águas subterrâneas, correlacionando estas variações com os períodos chuvosos e secos e, também, com as características locais. Atualmente 13 poços fazem parte da rede no Paraná, entretanto apenas os 10 poços mais antigos serão considerados, pois a série de dados nos 3 poços mais novos é curta, passível de distorcer a realidade nessa escala de trabalho.

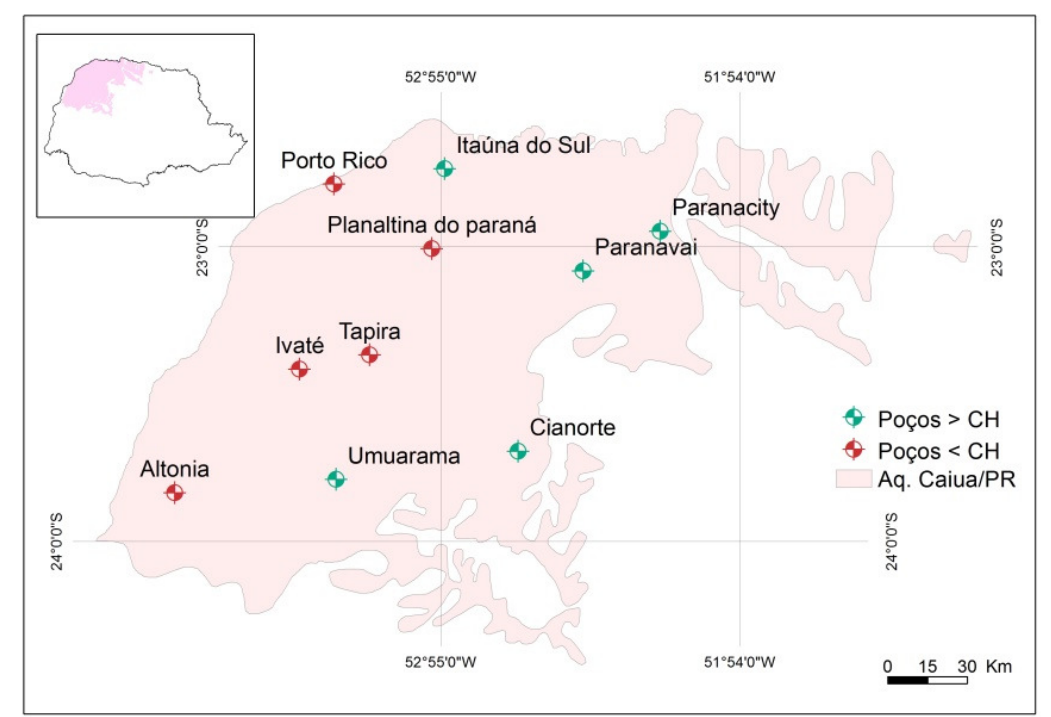

Figura 1. Mapa de localização dos poços da RIMAS no Aquífero Caiuá/PR

\section{2 - OBJETIVOS}

A integração dos dados pluviométricos com as variações dos níveis estáticos permite uma análise qualitativa dos períodos anuais de recarga e rebaixamento do aquífero, possibilitando diagnosticar a flutuação do nível estático correlacionando-o com o perfil litológico local.

A rede de poços no Caiuá permite a determinação do sentido do fluxo da água subterrânea. $\mathrm{O}$ aumento da mineralização a jusante pode ser determinado e interpretado. 


\section{3 - METODOLOGIA}

Para correlacionar os dados pluviométricos com as flutuações dos níveis da água foram utilizados dados de 3 poços de monitoramento situados nas cidades de Cianorte, Umuarama e Paranavaí. Estes dados foram colocados em gráficos com a intenção de facilitar a visualização da correlação das precipitações com as variações dos níveis estáticos ao longo do período de Setembro de 2011 a Agosto de 2015.

Em sequência foram utilizados os dados hidroquímicos das coletas realizadas em Julho/2015 dos 10 poços de monitoramento (Figura 1). As águas foram classificadas através do Diagrama de Piper e analisadas em conjunto com as cargas hidráulicas para permitirem uma análise dos enriquecimentos nos teores de cálcio, sódio, magnésio, resíduo seco e alcalinidade total ao longo do fluxo da água subterrânea no Aquífero Caiuá.

\section{4 - RESULTADOS}

A análise integrada da pluviometria com as variações nos níveis estáticos dos poços situados nas cidades de Cianorte (Figura 2), Umuarama (Figura3) e Paranavaí (Figura 4) demonstrou uma relação quase instantânea das precipitações de Junho e Julho sobre o nível estático de Cianorte e Umuarama e incipiente em Paranavaí. No restante dos meses predomina o rebaixamento do aquífero.

As maiores alturas médias mensais de precipitações para o período ocorreram nos meses de junho e julho (Tabela 1), cujos valores ultrapassam $160 \mathrm{~mm}$. O período entre setembro e maio também é chuvoso com média mínima de $128 \mathrm{~mm}$ em novembro. A maioria das chuvas mais intensas (acima de $100 \mathrm{~mm} /$ dia) também ocorreu no bimestre Junho/Julho, porém ocasionalmente essas precipitações também ocorreram em outros meses sem ter refletido com a mesma intensidade no nível estático, sugerindo que o conjunto do período chuvoso é necessário para efetuar uma recarga efetiva no aquífero.

Segundo o Instituto Paranaense de Águas, a média história anual para a região é próxima a $1425 \mathrm{~mm}$, valor coincidente com a média do período monitorado pela RIMAS que foi de $1580 \mathrm{~mm}$, porém a distribuição das chuvas ao longo do ano nesse período parece diferir da realidade histórica, pois nos últimos anos os verões foram mais secos e os invernos mais chuvoso, sugerindo uma inversão recente nos meses mais chuvosos. 


\begin{tabular}{|l|r|r|r|r|r|r|r|r|r|r|r|r|}
\hline \multicolumn{10}{|c|}{ DADOS PLUVIO MÉTRICOS mm/mês } \\
\hline MESES & $\mathbf{1}$ & $\mathbf{2}$ & $\mathbf{3}$ & $\mathbf{4}$ & $\mathbf{5}$ & $\mathbf{6}$ & $\mathbf{7}$ & $\mathbf{8}$ & $\mathbf{9}$ & $\mathbf{1 0}$ & $\mathbf{1 1}$ & $\mathbf{1 2}$ \\
\hline Cianorte & 211 & 158 & 199 & 125 & 137 & 206 & 180 & 21 & 85 & 180 & 127 & 177 \\
\hline Umuarama & 112 & 99 & 157 & 86 & 148 & 186 & 155 & 20 & 83 & 142 & 130 & 96 \\
\hline Paranavaí & 131 & 210 & 139 & 101 & 119 & 154 & 148 & 25 & 84 & 157 & 127 & 148 \\
\hline MÉDIA PERÍODO & $\mathbf{1 5 1}$ & $\mathbf{1 5 6}$ & $\mathbf{1 6 5}$ & $\mathbf{1 0 4}$ & $\mathbf{1 3 5}$ & $\mathbf{1 8 2}$ & $\mathbf{1 6 1}$ & $\mathbf{2 2}$ & $\mathbf{8 4}$ & $\mathbf{1 5 9}$ & $\mathbf{1 2 8}$ & $\mathbf{1 4 0}$ \\
\hline
\end{tabular}

Tabela 1. Média de chuva mensal entre setembro de 2011 e agosto de 2015

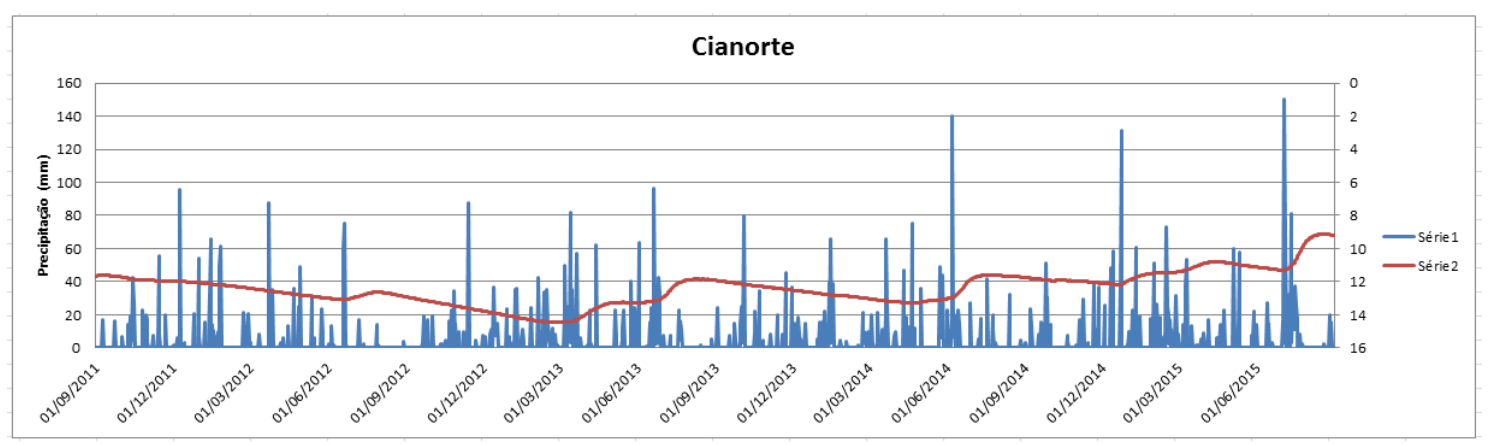

Figura 2. Precipitação x Nível Estático em Cianorte

Cianorte apresenta amplitude do nível estático de 5,34 m para o período analisado com o mínimo em 9,14 m e o máximo em 14,48 m, com as recargas bem marcadas nos meses de Junho e Julho coincidente com as maiores médias de precipitações anuais. No início de 2015 o nível estático sofreu uma leve recarga, pois os meses antecedentes (Novembro e Dezembro de 2014) tiveram chuva acima da média em relação aos anos anteriores (tabela 2). Este fator reforça que neste local a recarga é praticamente simultânea às precipitações.

\begin{tabular}{|c|r|r|}
\hline \multicolumn{2}{|c|}{ DADOS PLUVIOMÉTRICOS (mm/mês) } \\
\hline ANO & NO VEMBRO & \multicolumn{1}{|c|}{ DEZEMBRO } \\
\hline $\mathbf{2 0 1 1}$ & 103 & 183 \\
\hline $\mathbf{2 0 1 2}$ & 128 & 137 \\
\hline $\mathbf{2 0 1 3}$ & 125 & 76 \\
\hline $\mathbf{2 0 1 4}$ & 152 & 311 \\
\hline
\end{tabular}

Tabela 2. Média de chuva mensal de novembro e dezembro 


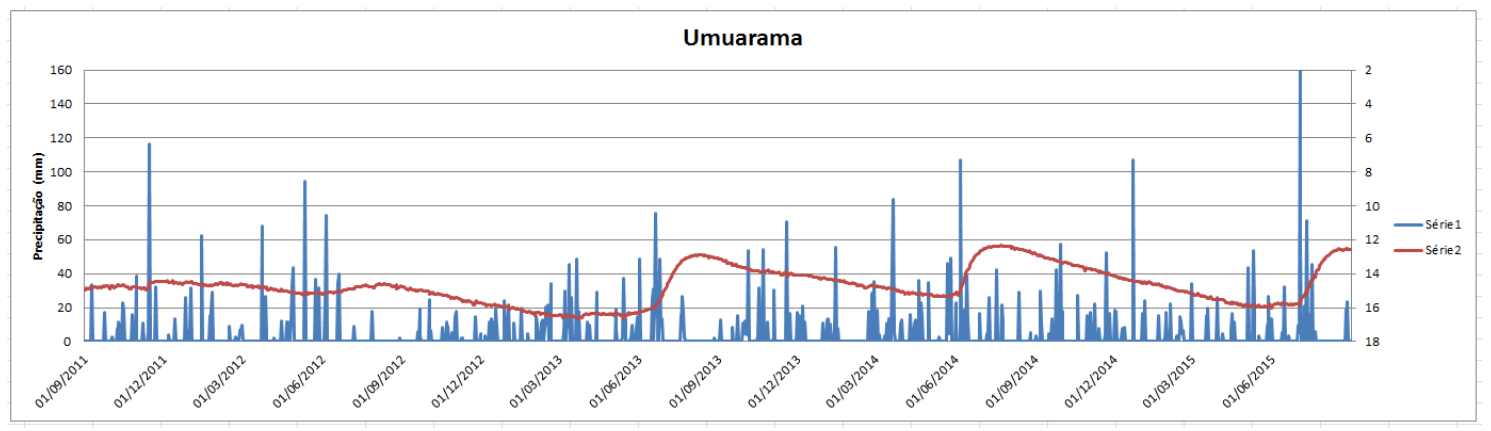

Figura 3. Precipitação x Nível Estático em Umuarama

O comportamento do aquífero em Umuarama é semelhante ao comportamento do aquífero em Cianorte, apresentando curvas semelhantes e recargas e rebaixamentos semelhantes. O nível estático mais raso registrado foi de 12,35 m e máximo de 16,65 m, tendo amplitude de 4,30 m, portanto pouco menor que em Cianorte, fato que pode ser explicado por Umuarama estar com o nível estático mais profundo e pela quantidade de chuva ter sido menor que em Cianorte no período considerado em cerca de $1500 \mathrm{~mm}$.

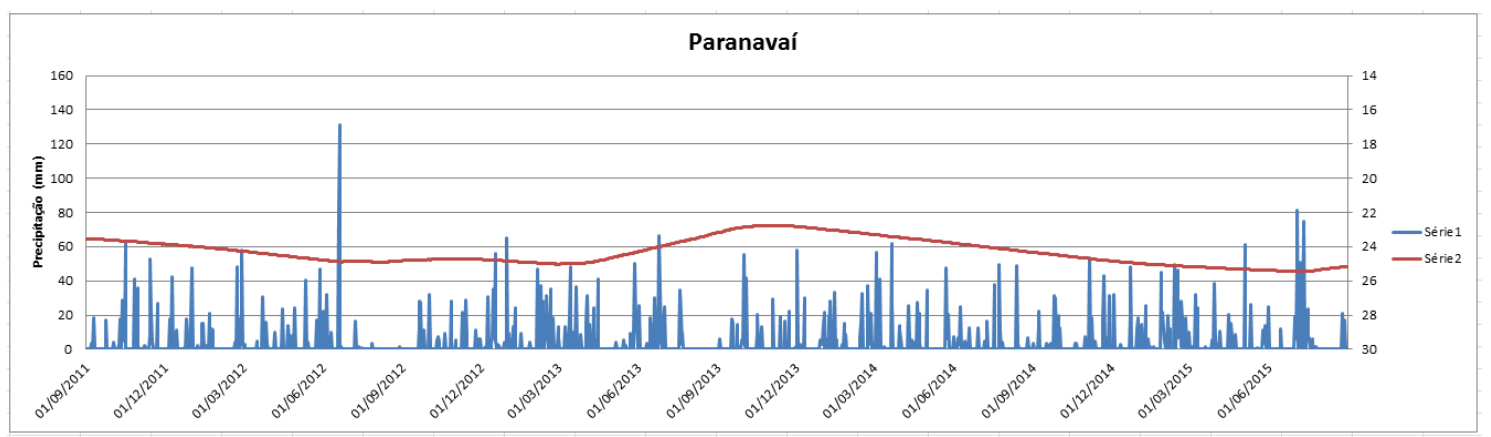

Figura 4. Precipitação x Nível Estático em Paranavaí

O Aquífero Caiuá em Paranavaí não demonstra a mesma influência da precipitação na recarga e no rebaixamento do nível da água, possivelmente influenciado pelo nível estático mais profundo, e pelo perfil litológico (Figura 5) apresentar argilosidade maior em relação aos poços anteriores de Cianorte e Paranavaí. 


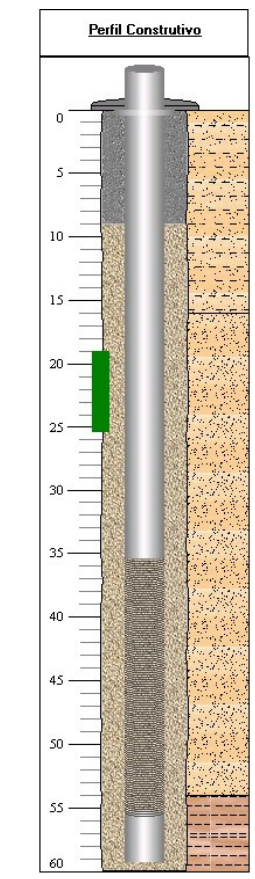

Figura 5. Perfil Litológico de Paranavaí

A classificação das águas através do diagrama de Piper (Figura 6) resulta em Cloretadas Magnesianas (4 poços), Cloretadas Sódicas (2 poços), Bicarbonatadas Sódicas (2 poços), Bicarbonatada Magnesiana (1 poços) e Bicarbonatada Cálcica (1 poço). Na literatura, as águas do aquífero Caiuá no Estado do Paraná são relatadas como bicarbonatadas cálcicas ou cálcio-magnesianas e raramente sódicas, mas ocorrem variações químicas significativas em função de variações litológicas, tais como a presença de cimentação calcífera e de resíduos de halita, e também da distribuição espacial sobre o substrato basáltico (Celligoi \& Duarte, 2002).

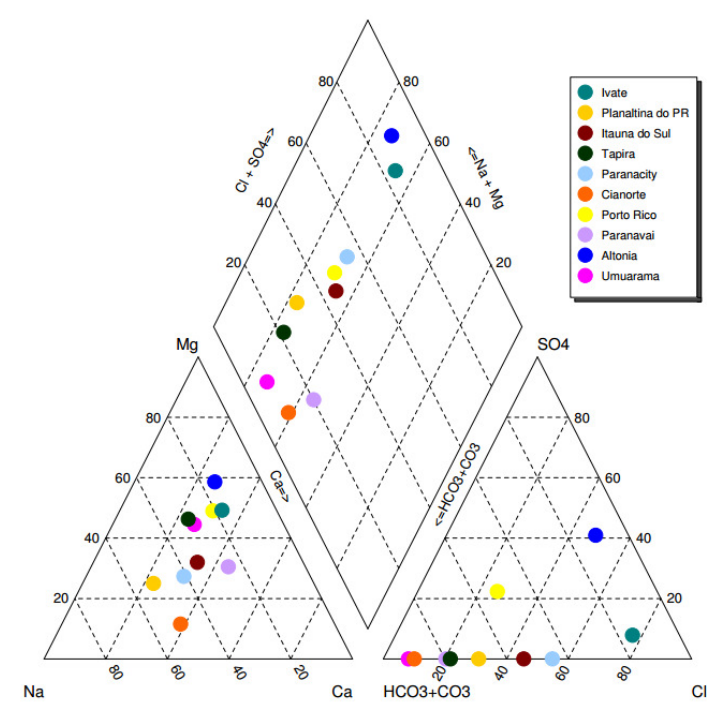

Figura 6. Diagrama de Pipper dos 10 Poços da RIMAS 


\begin{tabular}{|l|c|l|}
\hline \multicolumn{1}{|c|}{ MUNICÍPIO } & CARGA HIDRÁULICA (m) & \multicolumn{1}{c|}{ CLASSIFICAÇ̃̃O } \\
\hline Porto Rico & 279,45 & Cloretada Magnesiana \\
\hline Ivaté & 345,72 & Cloretada Magnesiana \\
\hline Tapira & 361,35 & Cloretada Magnesiana \\
\hline Planaltina do Paraná & 373,08 & Bicarbonatada Sódica \\
\hline Altônia & 374,24 & Cloretada Magnesiana \\
\hline Umuarama & 382,32 & Bicarbonatada Magnesiana \\
\hline Itaúna do Sul & 388,36 & Cloretada Sódica \\
\hline Paranacity & 412,74 & Cloretada Sódica \\
\hline Paranavaí & 454,62 & Bicarbonatada Cálcica \\
\hline Cianorte & 520,57 & Bicarbonatada Sódica \\
\hline
\end{tabular}

Tabela 3. Poços de monitoramento do Aquífero Caiuá no Estado do Paraná e respectivas cargas hidráulicas e classificação química.

Pôde-se constatar através da comparação entre os teores médios de $\mathrm{Na}, \mathrm{K}, \mathrm{Ca}, \mathrm{Mg}$ e $\mathrm{HCO}_{3}$ dos cinco poços com maior carga hidráulica (tabela 4) e dos cinco com menor carga hidráulica (tabela 5), um incremento nos teores de $\mathrm{HCO}_{3}, \mathrm{Na}$ e $\mathrm{K}$ (entre 1,28 e 2,90 vezes) dos poços de maior para os de menor carga. Ca e $\mathrm{Mg}$ apresentaram a maior diferença, de 3,91 e 7,85 vezes (tabela 6), respectivamente, demonstrando o aumento dos íons em direção a cargas hidráulicas mais baixas (poços geograficamente mais próximas à calha do Rio Paraná).

\begin{tabular}{|l|r|r|r|r|r|r|r|}
\hline Município & \multicolumn{1}{l|}{ C.H. } & Na & \multicolumn{1}{l|}{ K } & Ca & Mg & HCO3 & Resíduo Seco \\
\hline Cianorte & 520,57 & 0,37 & $<$ L.Q. & 0,25 & 0,05 & 1,74 & 8,00 \\
\hline Paranavaí & 454,62 & 1,00 & 3,07 & 1,55 & 0,64 & 8,55 & 34,00 \\
\hline Paranacity & 412,74 & 1,50 & 1,98 & 1,01 & 0,53 & 1,84 & 380,00 \\
\hline Itaúna do Sul & 388,36 & 0,56 & 2,05 & 0,48 & 0,28 & 3,43 & 32,00 \\
\hline Umuarama & 382,32 & 0,41 & 1,05 & 0,33 & 0,33 & 3,99 & 22,00 \\
\hline MÉDIA & & 0,77 & 2,04 & 0,72 & 0,37 & 3,91 & 95,20 \\
\hline
\end{tabular}

Tabela 4. Cinco maiores Cargas Hidráulicas (m) e suas respectivas concentrações iônicas em $\mathrm{mg} / \mathrm{L}$

\begin{tabular}{|l|r|r|r|r|r|r|r|}
\hline Município & C.H. & $\mathrm{Na}$ & $\mathrm{K}$ & $\mathrm{Ca}$ & $\mathrm{Mg}$ & \multicolumn{1}{l|}{ HCO3 } & Resíduo Seco \\
\hline Altônia & 374,24 & 1,83 & 4,64 & 2,71 & 3,69 & 1,34 & 76,00 \\
\hline Planaltina & 373,08 & 0,65 & 4,55 & 0,25 & 0,17 & 4,63 & 36,00 \\
\hline Tapira & 361,35 & 0,61 & 3,22 & 0,42 & 0,49 & 5,46 & 86,00 \\
\hline Ivaté & 345,72 & 3,97 & 10,40 & 6,55 & 5,86 & 4,65 & 156,00 \\
\hline Porto Rico & 279,45 & 3,30 & 6,73 & 4,20 & 4,12 & 8,92 & 130,00 \\
\hline MÉDIA & & 2,07 & 5,91 & 2,83 & 2,87 & 5,00 & 96,80 \\
\hline
\end{tabular}

Tabela 5. Cinco menores Cargas Hidráulicas (m) e suas respectivas concentrações iônicas em $\mathrm{mg} / \mathrm{L}$ 


\begin{tabular}{|c|c|c|c|c|c|c|c|}
\hline MÉDIAS E RAZ & $\begin{array}{l}5 \text { MAIO } \\
\text { AS RESP }\end{array}$ & $\begin{array}{l}\text { RES E } \\
\text { EC TIV }\end{array}$ & $\begin{array}{l}\text { DAS } 5 \\
\text { AS CO }\end{array}$ & $\begin{array}{l}\text { MENO } \\
\text { NCENT }\end{array}$ & $\begin{array}{l}\text { RES CA } \\
\text { RAÇ Õ E }\end{array}$ & $\begin{array}{l}\text { RGAS HI } \\
\text { S (mg/L) }\end{array}$ & $\mathbf{A S}(\mathrm{m})$ \\
\hline Médias & C.H. & $\mathrm{Na}$ & $\mathrm{K}$ & $\mathrm{Ca}$ & $\mathrm{Mg}$ & $\mathrm{HCO} 3$ & Resíduo Seco \\
\hline Média das > C.H. & 346,77 & 2,07 & 5,91 & 2,83 & 2,87 & 5,00 & 96,80 \\
\hline Média das < C.H. & 431,72 & 0,77 & 2,04 & 0,72 & 0,37 & 3,91 & 95,20 \\
\hline Razão <C.H./>C.H. & 0,80 & 2,70 & 2,90 & 3,91 & 7,85 & 1,28 & 1,02 \\
\hline
\end{tabular}

Tabela 6. A razão das C.H. demonstra o número de vezes que o íon foi aumentado

\section{5 - DISCUSSÕES}

As variações temporais no nível estático do Aquífero Caiuá nos 3 poços analisados são bem marcadas. Nos poços de Cianorte e Umuarama ocorre uma frequência anual, com recargas concentradas nos meses de Junho e Julho e rebaixamento ao longo do restante do ano. Chuvas concentradas influenciam rapidamente o aquífero demonstrando uma boa permeabilidade do substrato. Isso não se aplica a Paranavaí, pois a variação não é marcada ao longo do período de um ano, o nível mais profundo e a presença de argila no perfil do poço podem explicar esse comportamento.

Em relação à hidrogeoquímica, os resultados obtidos são coerentes com o modelo de evolução normal de uma água de circulação regional citado por Custodio \& Llamas (1983). Segundo este autor, em aquíferos com tendências regionais de enriquecimento salino vão dominando sucessivamente os seguintes cátions $\mathrm{Ca}^{+2}-\mathrm{Mg}^{+2}-\mathrm{Na}^{+}$.

Por outro lado, Campos (1993) considera que para o Sistema Aquífero Bauru/Caiuá não é nítido, regionalmente, o enriquecimento salino clássico acompanhado da evolução iônica conforme propõe alguns autores. Ele observa que o enriquecimento do teor salino das águas subterrâneas não é acompanhado pelo aumento dos teores de $\mathrm{Cl}^{-}$e de $\mathrm{Na}^{+}$, a não ser localmente. Neste caso, o autor propõe que os teores salinos estão sujeitos à influência das litologias carbonáticas do Grupo Bauru, enquanto que os teores mais elevados de $\mathrm{Na}^{+} \mathrm{e} \mathrm{Cl}^{-}$tenham relações com a proximidade com o substrato basáltico. 


\section{REFERÊNCIAS}

Celligoi, A.; Duarte, U. 2002. Hidrogeoquímica do Aquiúfero Caiuá no Estado do Paraná. p.19-32. Boletim Paranaense de Geociências, n.51.

Campos, H.C.N.S. 1993. Caracterização e cartografia das províncias hidrogeológicas do Estado de São Paulo. 177p. Tese de Doutorado. Instituto de Geociências, Universidade de São Paulo.

Custodio, E. \& Llamas, M. R. 1983. Hidrologia Subterrânea. 2a ed. Editora Ômega.

Instituto Paranaense de Águas. Disponível em: $<$ http://www.aguasparana.pr.gov.br/modules/conteudo/conteudo.php?conteudo=264>. Acesso em: 08/07/2016. 